\title{
ASSESSING GOING CONCERN ASSUMPTION BY USING RATING VALUATION MODELS BASED UPON ANALYTICAL PROCEDURES IN CASE OF FINANCIAL INVESTMENT COMPANIES
}

\author{
Tatiana Dănescu ${ }^{I}$ \\ Ovidiu Spătăcean ${ }^{2}$ \\ Paula Nistor ${ }^{3}$ \\ Andreea Cristina Dănescu ${ }^{4}$
}

\begin{abstract}
Designing and performing analytical procedures aimed to assess the rating of the Financial Investment Companies are essential activities both in the phase of planning a financial audit mission and in the phase of issuing conclusions regarding the suitability of using by the management and other persons responsible for governance of going concern, as the basis for preparation and disclosure of financial statements. The paper aims to examine the usefulness of recognized models used in the practice of financial standing, for the purpose of designing and applying analytical procedures specific to financial audit missions performed within Financial Investment Companies. This approach can serve as a basis in designing and developing specific financial audit programs for capital investments.
\end{abstract}

Key words: audit planning, Financial Investment Companies, analytical procedures, rating valuation, rating models, going concern.

JEL Code: $M 42$

Introduction

Financial audit missions conducted for Financial Investment Companies represent an essential precondition for ensuring healthy corporate governance structures, and to improve the transparency and credibility level in relation with investors, according to the principles accepted in the international context.

Rating assessment related to Financial Investment Companies is an essential approach in setting reasonable conclusions regarding the accuracy level of using the going concern assumption for preparing the financial statements of an entity. From the financial auditor's point of view, the going concern assumption involves the assertion according to which an entity is considered as having business continuity into the foreseeable future without the intent or the necessity of being liquidated, ceasing its transactions or seeking protection against creditors pursuant to legal requirements or other regulations. In consequence, assets and liabilities are recorded on the presumption that the reporting entity will be able to realize its assets and pay its debts in the due course of the business cycle (ISA 570).

From this perspective, the financial auditors may resort to usage of some models consecrated for rating assessment, modes that are based upon the development and performance of

\footnotetext{
${ }^{1}$ Profesor, Petru Maior University 1, Nicolae Iorga Street, 540088, Tg. Mures, ROMANIA, tatiana_danescu@yahoo.com

${ }^{2}$ Lecturer, Petru Maior University 1, Nicolae Iorga Street, 540088, Tg. Mures, ROMANIA, spatacean_ioanovidiu@yahoo.com

${ }^{3}$ PhD Student, Petru Maior University 1, Nicolae Iorga Street, 540088, Tg.Mures, ROMANIA, paaulan@yahoo.com

${ }^{4}$ PhD Student, "1Decembrie" University of Alba Iulia, , 11-13. N. Iorga Street, Alba Iulia, Romania,

andrea_danescu@yahoo.com
} 
analytical procedures. The analytical procedures require assessments of financial information through analyzing the plausible relations between financial and/or non - financial data. They contain those investigations, to the extent needed, regarding the fluctuations or the discordant relations in comparison with other relevant information or that differs by a significant amount as opposed to the expected values (ISA 520). The analytical procedures aim to analyze the existent correlations, the tendencies pertaining to analyzed informational elements, thus being able to assess the reasonable character of operations and account balances, by using comparisons and different indicators.

The analytical procedures are being applied from the audit planning phase but also during the final examination, emphasizing high risk fields of activity, for which, consequently, the financial auditor will use more detailed procedures, referred to as substantial tests. The performance of analytical procedures involves the following: developing tests and procedures that need to be performed, forecasting and comparing the information, analyzing the results, comparing and determining significant irregularities, especially those that are unexpected and projecting the adjustments related to the audit program (Danescu, 2007:138). If the analytical procedures identify fluctuations or relations that are not consequent with other relevant information or that differ by a significant amount as opposed to the expected values, the financial auditor must investigate such type of differences by inquiring the management and by collecting relevant and adequate audit evidence for the management's assertions and by performing other audit procedures as they are required under certain circumstances (ISA 520).

\section{Rating assessment models based on analytical procedures}

In the context of a increased price volatility that is felt more acutely in international financial markets, implicit in the Romanian capital market, the credibility level associated with financial auditor profession becomes more than a necessity. Financial audit missions are regarded as a guarantor of the integrity of the information presented in financial statements, to the extent that the audit quality and efficiency features are provided through adequate tests and procedures to ensure obtaining sufficient and appropriate audit evidence to support the auditor's conclusions and finally, the auditor's opinion. The rating valuation models based upon analytical procedures may be used in an financial audit mission for the purpose of obtaining a "financial picture" of the audited entity and collecting relevant audit evidence when drawing general conclusions regarding the entity's capacity to conduct business operations on a going concern basis.

As an integral part of planning, performing tests and procedures and assessing the audit evidence regarding the results of applied audit procedures, the financial auditor is responsible of taking into consideration the entity's management adequacy in using the going concern principle that the preparation of financial statements underlies on, paying a special attention to audit evidence related to events, activity conditions and risks that could generate significant uncertainties over the entity's capacity of continuing its operations. From this point of view, the consecrated models for rating assessment within an entity may demonstrate their usefulness, as follows:

(a) Financial Standing Model: is based on determining and analyzing some key financial indicators synthesized in: profitability rates, rotation indicators of current assets, liquidity and solvency indicators, market indicators (EPS, PER, Dy) and dynamic indicators such as performance related to investment operations.

(b) Altman Model: combines different financial rates with the purpose of measuring the probability of insolvency occurrence. In a general approach, the smaller the obtained score, the greater the entity's "chance" to go bankrupt. The companies with score function $(Z)$ over the value of 3 as considered as being healthy in terms of financial aspects, with a low probability of going bankrupt. The score between 1.8 and 3 is situated in a grey area and the one below 1.8 is considered to cause serious financial difficulties. 
(c) Robertson Model: the score function takes into account four elements that lead to changes into the entity's "financial health": market stability, profit decrease, decrease in the working capital, and loan increase. Score function $\mathrm{Z}$ is concerned with the modifications that occur into the entity's financial position, in a dynamic approach. Thus, if $\mathrm{Z}$ score depreciates over one year period by $40 \%$ or more, the rating analysis must identify the variation causes. If $\mathrm{Z}$ score's depreciation tendency persists on a period greater than one year period, with the same intensity in decrease (over 40\%), one may assess that the entity is not able to survive due to its financial instability.

(d) BRD Model: takes into account the entity classification in one of the five reliability categories, which are practically appreciation qualifications applied to financial performances based upon the following indicators: indebtedness level, immediate liquidity, long term solvency, investment operations' profitability and expenses' coverage from incomes.

(e) Banca Transilvania Model: is based upon determining a $\mathrm{Z}$ score function that resembles the one specific to BRD model, yet by taking into account certain indicators that are closer to the entity's current activities: net margin and gross exploitation margin, indebtedness level, current liquidity rate and current assets' turnover.

\section{Hypotheses and research approach}

The projection and performance of analytical procedures for rating assessment of Financial Investment Companies requires the opening of new horizons into the knowledge field of this activity. Under this motivation, a research approach had been taken into consideration, which aims to the identification of rating assessment models related to Financial Investment Companies that use analytical procedures. The purpose of such a research approach consists of drawing conclusions regarding the capacity of the analyzed entities to continue with their activity in financial security conditions.

The methodological research approach mainly took into account the assessment of financial performances and position, by the analysis of financial statements issued by the five Financial Investment Companies in the period 2005-2009, the appreciations of qualifications obtained for different score functions attached to consecrated models of rating analysis (Altman, Financial Standing, Robertson, BRD or Banca Transilvania), as well as inspecting the trading reports issued by the market operator Bucharest Stock Exchange and the analysis reports issued by the Association of Fund Administrators in Romania. The results may be regarded as valuable audit evidence that allow the financial auditor to draw relevant conclusions regarding the "financial health" of Financial Investment Companies, as an essential assumptions in the process of assessing the going concern accuracy level.

\section{Research activities related to assessment of going concern for Financial Investment Companies}

The research performed aims to assess the ability of Financial Investment Companies to continue their operations under financial security conditions, based on rating assessment. The research approach was based upon performing analytical and valuation procedures in relation with the financial statements prepared by the Financial Investment Companies over the period 20052009. Primary data was collected from the balance sheet, profit and loss account and the explanatory notes to the financial statements. In consequence we were able to obtain qualifications that were associated to some distinct assessment methodologies regarding an entity's rating.

As a result of data processing regarding the financial position and performances of the Financial Investment Companies the following findings may be summarized regarding the qualifications obtained: 
Results obtained following tests undertaken for rating models

Table no. 1 .

\begin{tabular}{|c|c|c|c|c|c|c|}
\hline \multirow[t]{2}{*}{ Entity } & \multirow[t]{2}{*}{ Period } & \multicolumn{5}{|c|}{ Rating Model Used } \\
\hline & & $\begin{array}{l}\text { Financial } \\
\text { Standing }\end{array}$ & Altman & Robertson & BRD & $\begin{array}{c}\text { Banca } \\
\text { Transilvania }\end{array}$ \\
\hline \multirow{5}{*}{$\begin{array}{l}\text { Banat } \\
\text { Crisana FIC }\end{array}$} & 31.12 .2005 & $\mathrm{~B}$ & $\mathrm{~S}$ & - & FB & $\mathrm{B}$ \\
\hline & 31.12 .2006 & FB & $\mathrm{S}$ & $\mathrm{S}$ & FB & FB \\
\hline & 31.12 .2007 & FB & $\mathrm{S}$ & $\mathrm{D}$ & FB & FB \\
\hline & 31.12 .2008 & $\mathrm{~B}$ & $S$ & $\mathrm{~F}$ & FB & $\mathrm{B}$ \\
\hline & 31.12 .2009 & FB & $\mathrm{S}$ & $\mathrm{S}$ & FB & FB \\
\hline \multicolumn{2}{|c|}{ General appreciation } & B & $\mathbf{S}$ & $\mathbf{D}$ & FB & B \\
\hline \multirow[t]{5}{*}{ Moldova FIC } & 31.12 .2005 & $\mathrm{~B}$ & $S$ & - & FB & $\mathrm{B}$ \\
\hline & 31.12 .2006 & $\mathrm{~B}$ & $\mathrm{~S}$ & $\mathrm{~S}$ & FB & FB \\
\hline & 31.12 .2007 & FB & $S$ & $\mathrm{D}$ & FB & FB \\
\hline & 31.12 .2008 & FB & $\mathrm{S}$ & $\mathrm{S}$ & FB & FB \\
\hline & 31.12 .2009 & FB & $\mathrm{S}$ & $\mathrm{S}$ & FB & FB \\
\hline \multicolumn{2}{|c|}{ General appreciation } & $\mathbf{B}$ & $\mathbf{S}$ & $\mathbf{S}$ & FB & FB \\
\hline \multirow{5}{*}{$\begin{array}{l}\text { Transilvania } \\
\text { FIC }\end{array}$} & 31.12 .2005 & $\mathrm{~B}$ & $\mathrm{~S}$ & - & FB & $\mathrm{B}$ \\
\hline & 31.12 .2006 & $\mathrm{~B}$ & $\mathrm{~S}$ & $\mathrm{D}$ & FB & FB \\
\hline & 31.12 .2007 & FB & $\mathrm{S}$ & $\mathrm{S}$ & FB & FB \\
\hline & 31.12 .2008 & $\mathrm{~B}$ & $S$ & $\mathrm{~S}$ & FB & $\mathrm{B}$ \\
\hline & 31.12 .2009 & FB & S & S & FB & FB \\
\hline \multicolumn{2}{|c|}{ General appreciation } & B & $\mathbf{S}$ & $\mathbf{S}$ & FB & B \\
\hline \multirow{5}{*}{$\begin{array}{l}\text { Muntenia } \\
\text { FIC }\end{array}$} & 31.12 .2005 & $\mathrm{~B}$ & $\mathrm{~S}$ & - & $\mathrm{B}$ & FB \\
\hline & 31.12 .2006 & $\mathrm{~B}$ & $\mathrm{~S}$ & $\mathrm{~S}$ & FB & $\mathrm{B}$ \\
\hline & 31.12 .2007 & $\mathrm{~B}$ & $S$ & $\mathrm{D}$ & FB & $\mathrm{B}$ \\
\hline & 31.12 .2008 & B & $\mathrm{S}$ & $\mathrm{S}$ & FB & $\mathrm{B}$ \\
\hline & 31.12 .2009 & $\mathrm{~B}$ & $\mathrm{~S}$ & $\mathrm{D}$ & FB & B \\
\hline \multicolumn{2}{|c|}{ General appreciation } & B & $\mathbf{S}$ & D & FB & B \\
\hline \multirow[t]{5}{*}{ Oltenia FIC } & 31.12 .2005 & $\mathrm{~B}$ & $\mathrm{~S}$ & - & FB & $\mathrm{B}$ \\
\hline & 31.12 .2006 & $\mathrm{FB}$ & $\mathrm{S}$ & $\mathrm{S}$ & FB & $\mathrm{B}$ \\
\hline & 31.12 .2007 & FB & $\mathrm{S}$ & $\mathrm{S}$ & FB & $\mathrm{B}$ \\
\hline & 31.12 .2008 & $\mathrm{~B}$ & $\mathrm{~S}$ & $\mathrm{D}$ & $\mathrm{B}$ & FB \\
\hline & 31.12 .2009 & $\mathrm{FB}$ & $\mathrm{S}$ & $\mathrm{S}$ & $\mathrm{FB}$ & FB \\
\hline \multicolumn{2}{|c|}{ General appreciation } & B & $\mathbf{S}$ & $\mathbf{S}$ & FB & B \\
\hline
\end{tabular}

Source: authors' projection

Legend: B - good, FB - very good, S - solvable, D - difficulty, F - bankrupt

Note: Within the appreciation of the general qualification, an attitude of professional skepticism had been taken into account, which is specific to the practice of financial audit.

If subsequent the application of rating models related to the Financial Investment Companies, models that are based upon projected analytical procedures, are identified events, conditions or potential risk factors that could raise significant uncertainties upon the capacity of continuing the investment operations under normal business conditions, the financial auditor must project and apply additional audit procedures, such as the following:

(a) Examining the management's operational plans based upon own assessments regarding going concern. Such operational plans could refer to rationalization of current expenses, selling significant stocks, optimizing the trading strategies or revising the investment objectives; 
(b) Obtaining sufficient and adequate audit evidence to confirm or infirm that there is a significant uncertainty, including taking into account the effect of management plans and other contraction factors, such as increased volatility of trading prices or decreased liquidity of the market;

(c) Analyzing and debating with the management the cash flows derived from investment activities, the earnings from trading financial assets and other relevant forecasting, including the most recently interim financial statements available;

(d) Examining the minutes related to General Meeting of the Shareholders, to meetings of those in charge with governance or other relevant committees, for any references related to financial difficulties that are caused by financial instrument trading operations;

(e) Questioning the entity's compliance officer regarding litigations and claims to offsets, which are declared by the financial creditors, as well as the reasonableness of their assessments and estimates of financial consequences;

(f) Analyzing subsequent events for identification of those elements that either diminish or affect in any other ways the entity's capacity of continuing its operations on a going concern basis.

(g) Comparing the forecast financial information for the recently ended periods with historical results, including the forecast financial information for the current period with the outcomes achieved so far.

\section{Conclusions}

Analyzing data obtained from rating valuation tests and based upon those considerations issued over the recorded qualifications, we may draw few relevant conclusions to this survey:

- In a general approach, there is a convergence tendency of the results obtained, in the sense of confirming a certain state of financial health. Actually, for Moldova FIC, Transilvania FIC and Oltenia FIC, the qualifications obtained under all selected rating models emphasize an appropriate financial health state. These conclusions are extremely precious for the preliminary assessment of the management's compliance under going concern assumptions, as basis for preparing the financial statements.

- Under special circumstances, the results obtained differ significantly in relation with each selected rating model, for the same analyzed entity. Thus, for example, we must retain that for Banat Crisana FIC and Muntenia FIC, different financial security levels were obtained, starting with the qualification that express financial difficulties and continuing up to the most adequate level. Within this context, a prudential attitude is required from the financial auditor, when audit evidence is assessed, as it is imperatively necessary to go deeper into the matter, based upon key financial indicators.

- An extended level of usefulness may be associated to conceiving and applying such analytical procedures as substantial procedures, with the purpose of issuing judgment considerations over the quality of specific activities related to portfolio management. In consequence, the financial auditor is capable of drawing general conclusions regarding the extent to which financial statements are coherent with the entity's general understanding and that they do not contain significant irregularities that would determine the financial auditor to modify the audit report.

The rating valuation models based upon analytical procedures may prove extremely effective in facilitating auditor's understanding of the operating environment specific to Financial Investment Companies and allow the financial auditor to test the recognition, measurement and presentation of financial assets in the financial statements, accounting policies selected and applied by the management in this regard. From this perspective, the use of specific methods and tools for analyzing financial standing may be regarded as a necessity to define the quality of audit missions in the spirit of public interest. 


\section{References:}

1. Bătrâncea M., Bătrâncea L.M., 2006. Financial - Banking Standing, Risoprint Publishing House, Cluj Napoca

2. International Federation of Accountants. Chamber of Financial Auditors in Romania, 2009, A handbook of International Standards in Quality Audit and Control. Financial audit 2009, Irecson Publishing House, Bucharest

3. Marchetti A. M., 2005. Beyond Sarbanes - Oxley Compliance. Effective enterprise risk management, John Wiley \& Sons Inc. Publishing House, Hoboken, New Jersey

4. Danescu, T., 2007. Procedures and Techniques in Financial Audit, Irecson Publishing House, Bucuresti

5. Whittington O. R., Pany K., 2006. Principles of auditing and other assurance services Fifteenth Edition, McGraw Publishing House - Hill / Irwin, New York

6. www.banat-crisana.com, www.sifm.ro, www.transif.ro, www.sifmuntenia.ro, www.sifolt.ro, www.bvb.ro. 